\title{
Discrimination among pest species of Bactrocera (Diptera: Tephritidae) based on PCR-RFLP of the mitochondrial DNA
}

\author{
Masahiko Muraji* and Shigehito Nakahara ${ }^{1,2}$ \\ National Institute of Agrobiological Sciences, Tsukuba, Ibaraki 305-8634, Japan \\ ${ }^{1}$ Yokohama Plant Protection Station, Yokohama, Kanagawa 231-0003, Japan \\ (Received 16 January 2002; Accepted 8 May 2002)
}

\begin{abstract}
A PCR-RFLP based method of species identification was considered for 18 pest species of Bactrocera fruit flies mainly distributed in the Asia-Pacific region. A $1.6 \mathrm{~kb}$ portion of the mitochondrial DNA containing portions of $16 \mathrm{~S}$ and $12 \mathrm{~S}$ ribosomal RNA genes was determined for eight species for which the mtDNA sequences have not been studied. Comparisons of restriction patterns expected from the sequences obtained in this and previous studies revealed that all 18 species can be discriminated by PCR-RFLP using a small number of restriction enzymes. Based on the highly conserved sequences detected among the 18 species, four sets of PCR primers were designed to amplify shorter, diagnostically informative sections within the mtDNA fragment. Given the simplicity of banding patterns and the ease of amplification of DNA fragments, such sections were considered suitable for PCR-RFLP analysis. Based on the results, a scheme for the Bactrocera pest species identification was proposed. The PCR-RFLP analysis using 83 individuals revealed that the scheme correctly identified most of the 18 species except for two closely related sympatric species, Bactrocera carambolae and B. papayae; the majority of individuals of the former species showed the same banding patterns as the latter species. In addition, molecular phylogenetic analyses were performed based on the nucleotide sequences in order to examine the positioning of each species among many other species of fruit flies.
\end{abstract}

Key words: Mitochondrial DNA, PCR-RFLP, species identification, Bactrocera, Tephritidae

\section{INTRODUCTION}

The tephritid genus Bactrocera is widely distributed in the Asia-Pacific region and contains a number of economically important species that cause losses in fruit and vegetable crops. Among 11 species of Japanese Bactrocera, the two major pest species, the oriental fruit fly Bactrocera dorsalis and the melon fly B. cucurbitae, were eradicated from the country (Yoshizawa, 1997). However, as a result of increased importation of fruits and vegetables in recent years, fruit flies of foreign origins have been frequently intercepted at quarantine inspection sites. Consequently, it has become increasingly important to take precautions against their invasion.

To that end, it is necessary to identify pest species accurately. Traditionally, they have been identified based on the morphological characteristics of adult insects (White and Hancock, 1997). However, it is sometimes difficult to identify Bac- trocera species, because there are numbers of species that are not morphologically distinct. Moreover, there are many cases in which morphological criteria cannot be easily applied. For example, species identification of immature insects usually requires rearing individuals until adult emergence. Many species can be discriminated from allied species only by the characteristics of male adults. Species identification is difficult when only broken pieces or portions of insect body are available. Such situations necessitate the development of new criteria for rapid and accurate identification of Bactrocera species that can be applied in quarantine practices.

Recently, a number of entomologists have analyzed the nucleotide sequences of fruit flies to infer phylogenetic relationships among species and groups (Han and McPheron, 1997; Smith and Bush, 1997; Han, 2000; Muraji and Nakahara, 2001). As a result, several hundred sequences were submitted to international DNA sequence data-

\footnotetext{
* To whom correspondence should be addressed at: E-mail: mmuraji@affrc.go.jp

2 Present address: Naha Plant Protection Office, Naha, Okinawa 900-0001, Japan
} 
bases such as DDBJ, EMBL, and GenBank. These sequences can be used to design methods of species identification based on PCR-RFLP (Restriction fragment length polymorphisms in DNA fragments amplified by polymerase chain reaction), though such an analysis has not yet been performed for Bactrocera species.

In this study, we sequenced a $1.6 \mathrm{~kb}$-long portion of mitochondrial DNA (mtDNA) using 19 individuals from eight Bactrocera pest species mainly distributed in the Oceanian region (i.e., B. tryoni, $B$. frauenfeldi, B. musae, B. cucumis, B. neohumeralis, $B$. jarvisi, B. curvipennis, and $B$. psidi). Using these and reported sequences of major pest species in the Oriental region, RFLP patterns were estimated and compared in order to develop a PCRRFLP-based method of species identification. The utility of the method was improved by using shorter sections within the sequence amplified by PCR primers designed according to the distribution of recognition sites of diagnostic restriction enzymes. In addition, we also performed molecular phylogenetic analyses based on the sequences in order to examine the positioning of each species among many species of fruit flies.

\section{MATERIALS AND METHODS}

Materials used in this study are listed in Table 1. Template DNA for sequencing and PCR-RFLP analyses was extracted from whole body or portions (mainly legs) of individual adults using a GenomicPrep $^{\text {TM }}$ Cells and Tissue DNA Isolation Kit (Amersham Pharmacia). Template DNAs were dissolved in 200 or $50 \mu \mathrm{l}$ of sterilized water. Using 19 individuals of eight Oceanian species, the nucleotide sequence of the PCR amplified fragment (1.6 kb long) was analyzed. Experimental procedures for amplification, purification, labeling, and sequencing were the same as those described in Muraji and Nakahara (2001). Nucleotide sequences obtained were submitted to DDBJ/EMBL/GenBank nucleotide sequence databases (Accession numbers; AB074018-AB074029).

The sequences were aligned with those of 10 previously reported species of Bactrocera (described at the end of this section) and three other dipteran insects, the fruit fly Drosophila yakuba (X03240), the Mediterranean fruit fly Ceratitis capitata (AJ242872), and the Mexican fruit fly
Anastrepha ludens (AB035102), using the program TreeAlign (Hein, 1990) with default parameters $($ gapa $=8$, gapb $=3)$. For phylogenetic analyses, ambiguously aligned portions (226 bp in total length, including gaps) were excluded from the alignment, and consistently aligned sequences $(1,458 \mathrm{bp})$ were analyzed using PAUP* Version 4.0 b8 (Swofford, 1999) and MEGA version 1 (Kumar et al., 1993). In the weighted parsimony analysis using PAUP, a weighting scheme generated using the "REWEIGHT" command with an "index $=\mathrm{RC}$ " option, treating the consensus tree of the unweighted parsimony analysis as the starting tree, was applied. The support for each node was assessed by 1,000 replications of bootstrapping, using a 100 maxtree option.

For 43 sequences of the 18 species obtained in this and previous studies (Muraji and Nakahara, 2001), recognition sites of 50 restriction enzymes were estimated using the computer program Genetyx-Mac Version 10.1 (Software Development). Based on the distribution of diagnostic restriction sites and on the homology in the aligned sequences, four sets of PCR primers ( 8 primers in total) were designed to amplify diagnostically informative sections within the mtDNA fragment. PCR products obtained using these primers were used for the PCR-RFLP analyses. In order to test the efficiency of the primers, PCR was also performed using several dried specimens (B. dorsalis and B. cucurbitae) left at room temperature for more than 4 months. Amplification was carried out under the experimental conditions described in Muraji and Nakahara (2001). Two to $4 \mu \mathrm{l}$ of the PCR product was incubated in a total reaction volume of $10 \mu \mathrm{l}$ containing $2 \mathrm{U}$ restriction enzyme, AseI, DraI (Nippon Gene), ApoI, or MseI (NEW ENGLAND BioLabs), and $1 \times$ reaction buffer for $2 \mathrm{~h}$ at $37^{\circ} \mathrm{C}$ (or $50^{\circ} \mathrm{C}$ for ApoI). Restriction fragments $(5 \mu \mathrm{l}$ of reaction mixture) were electrophoresed in 2, 4, or 4.5\% MetaPhor $^{\mathrm{TM}}$ agarose (BioWhittaker Molecular Applications) gel in $1 \times$ TBE buffer at $6-7 \mathrm{~V} / \mathrm{cm}$ for $2 \mathrm{~h}$ then visualized by staining with ethidium bromide.

Species and accession numbers of the sequences used in phylogenetic and restriction fragment analyses were as follows: $B$. carambolae (AB035117, AB035118), B. dorsalis (AB035114, AB035115, AB035116), B. kandiensis (AB048737, AB048738), B. occipitalis (AB048741, AB048742), 
Table 1. Specimens used in this study

\begin{tabular}{|c|c|c|c|}
\hline Subgenus & Species $^{\mathrm{a}}$ & Collection site ${ }^{\mathrm{b}}$ & Analysis performed $^{\mathrm{c}}$ \\
\hline Afrodacus & B. jarvisi & Queensland, Australia & PCR-RFLP (3) / Sequencing (2) \\
\hline Austrodacus & B. cucumis & Queensland, Australia & PCR-RFLP (3) / Sequencing (3) \\
\hline \multirow[t]{24}{*}{ Bactrocera } & B. curvipennis & New Caledonia & PCR-RFLP (2) / Sequencing (2) \\
\hline & B. frauenfeldi & Queensland, Australia & PCR-RFLP (2) / Sequencing (2) \\
\hline & B. musae & Queensland, Australia & PCR-RFLP (2) / Sequencing (2) \\
\hline & B. neohumeralis & Queensland, Australia & PCR-RFLP (2) / Sequencing (2) \\
\hline & B. psidi & New Caledonia & PCR-RFLP (3) / Sequencing (3) \\
\hline & B. tryoni & Queensland, Australia & PCR-RFLP (2) / Sequencing (2) \\
\hline & & New Caledonia & PCR-RFLP (1) / Sequencing (1) \\
\hline & B. carambolae* & Kuala Lumpur, Malaysia & PCR-RFLP (1) \\
\hline & & Pattani, Thailand & PCR-RFLP (3) \\
\hline & & Nakhon Si, Thailand & PCR-RFLP (2) \\
\hline & & Bandung, Indonesia & PCR-RFLP (3) \\
\hline & B. dorsalis* & Amami, Kagoshima, Japan & PCR-RFLP (5) \\
\hline & & Naha, Okinawa, Japan & PCR-RFLP (5) \\
\hline & & Ogasawara, Tokyo, Japan & PCR-RFLP (5) \\
\hline & B. kandiensis* & Katunayake, Sri Lanka & PCR-RFLP (3) \\
\hline & B. occipitalis* & Narita Airport (Philippines) & PCR-RFLP (1) \\
\hline & & Nagoya Airport (Philippines) & PCR-RFLP (1) \\
\hline & & Cebu, Philippines & PCR-RFLP (2) \\
\hline & & Davao, Philippines & PCR-RFLP (3) \\
\hline & B. papayae* & Kuala Lumpur, Malaysia & PCR-RFLP (1) \\
\hline & & Pattani, Thailand & PCR-RFLP (3) \\
\hline & & Bandung, Indonesia & PCR-RFLP (5) \\
\hline & B. philippinensis* & Narita Airport (Philippines) & PCR-RFLP (4) \\
\hline & & Davao, Philippines & PCR-RFLP (3) \\
\hline Tetradacus & B. tsuneonis & Oita, Japan & PCR-RFLP (3) \\
\hline \multirow[t]{6}{*}{ Zeugodacus } & B. cucurbitae & Amami, Kagoshima, Japan & PCR-RFLP (1) \\
\hline & & Naha, Okinawa, Japan & PCR-RFLP (1) \\
\hline & & Sri Lanka ${ }^{\mathrm{d}}$ & PCR-RFLP (1) \\
\hline & B. depressa & Nago, Okinawa, Japan & PCR-RFLP (1) \\
\hline & & Yokohama, Kanagawa, Japan & PCR-RFLP (1) \\
\hline & B. tau & Kegalla, Sri Lanka & PCR-RFLP (4) \\
\hline
\end{tabular}

${ }^{\text {a }}$ Species denoted by an asterisk belong to the Bactrocera dorsalis complex.

${ }^{\mathrm{b}}$ The country that exported fruits from which Bactrocera fruit flies were detected is shown in parentheses.

${ }^{\mathrm{c}}$ Numerals in parentheses refer to the number of individuals used for sequencing and PCR-RFLP analyses.

${ }^{\mathrm{d}}$ A laboratory strain established using insects collected at Puttalam, Negombo, and Dumbulla in Sri Lanka.

B. papayae (AB035119, AB035120), B. philippinensis (AB035111, AB048743, AB048744), B. depressa (AB035100, AB035101), B. cucurbitae (AB035112, AB035113, AB048754, AB048748), B. tau (AB048745, $\mathrm{AB} 048746)$, and B. tsuneonis (AB074030).

\section{RESULTS}

\section{Sequence alignment}

Among the 18 species treated in this study, mtDNA sequences had not been previously studied for eight species distributed mainly in the Oceanian region. For such species, we successfully determined 1,599-1,601 bp-long sequences using 19 individuals. Nucleotide composition of these sequences was biased for $\mathrm{A}$ and $\mathrm{T}$, and showed an average $\mathrm{A}+\mathrm{T}$ content of $77.6 \%$ (range: $73.5-78.4 \%$ ). When the sequences were aligned with those of 10 previously reported Bactrocera fruit flies and the three other dipteran species, at least 17 sites of insertion/deletion mutations were detected. Due to this phenomenon, these sequences could not be aligned unambiguously in such portions. Thus, for phylogenetic analyses, 17 ambiguously aligned portions (226 bp in total length including gaps) 


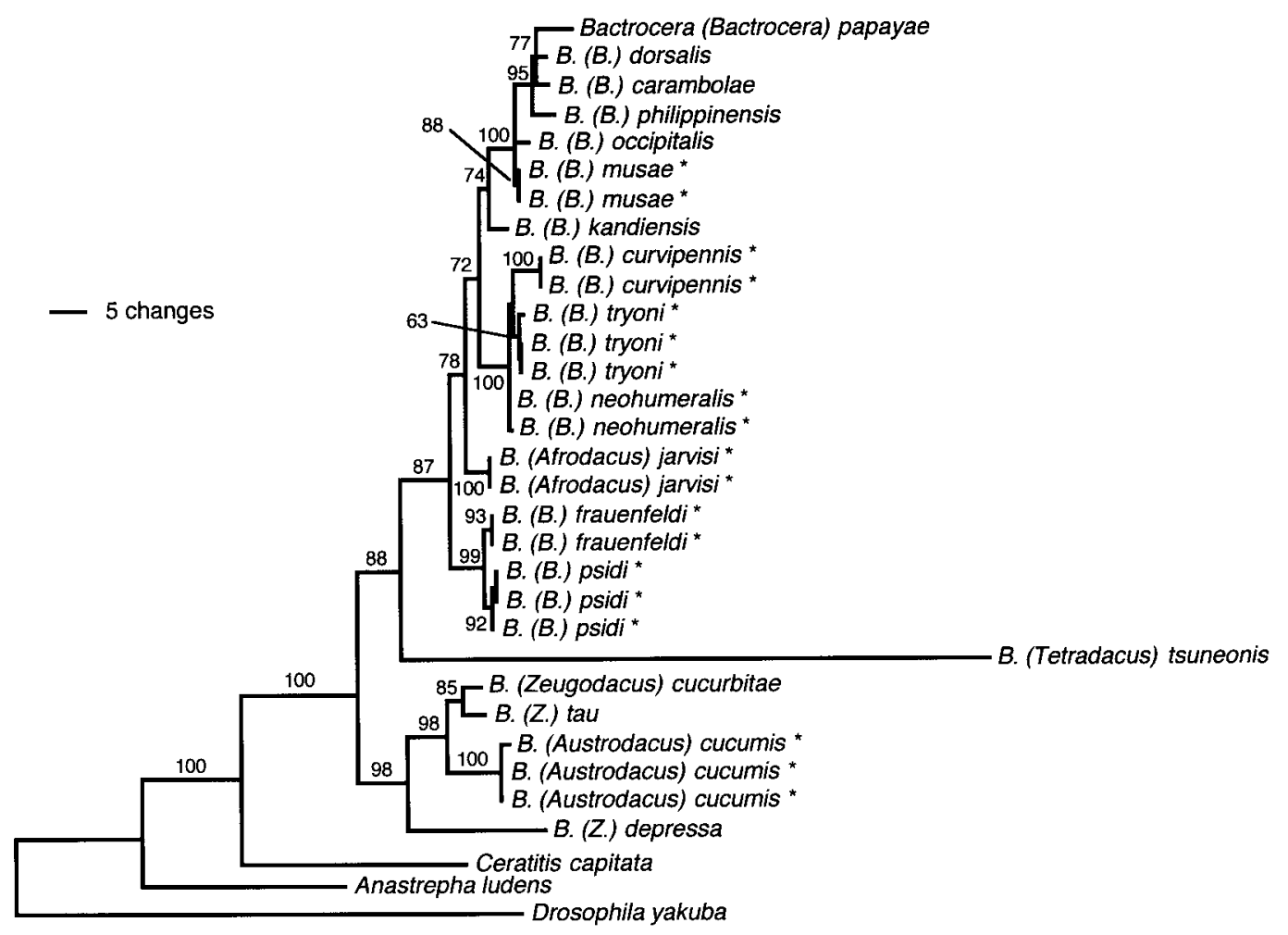

Fig. 1. One of the two most parsimonious trees generated by the weighted parsimony analysis based on consistently aligned $1,458 \mathrm{bp}$-long sequences. Nucleotide sequences of species denoted by an asterisk were obtained in this study.

were excluded from the alignment according to the method described by Muraji and Nakahara (2001).

\section{Phylogenetic analysis}

Phylogenetic analyses were performed using 1,458 bp-long aligned sequences from which ambiguously aligned sections were excluded. In the case of the maximum parsimony analysis, the unweighted method generated the two most parsimonious trees (length: 577 steps, CI: 0.759) based on 145 parsimony-informative characters. Analysis using the character weighting also generated the two most parsimonious trees (length: 382 steps, CI: 0.907) (Fig. 1). Among trees, differences were observed only in the relationships between the closely related species $B$. dorsalis, B. papayae, and $B$. carambolae within the same clade. In these trees, many of the phylogenetic relationships were supported by bootstrap analysis. In the case of neighbor-joining analyses, topologies generated based on Jukes-Cantor, Tamura, Tamura-Nei, and Kimura 2-parameter distances were in agreement. When only nodes supported by bootstrap confidence levels of higher than $50 \%$ were considered, neighbor- joining trees agreed well with those generated by the weighted parsimony method except in the case of the positioning of $B$. tsuneonis.

\section{PCR-RFLP analysis}

For 43 sequences of the 18 Bactrocera species obtained in this and previous studies (Muraji and Nakahara, 2001), recognition sites of 50 restriction enzymes were examined using the computer program Genetyx (data not shown). Restriction patterns expected from the sequences revealed that all 18 species could be discriminated among by PCRRFLPs with MseI and several other restriction enzymes (ApoI and AluI or Sau3AI). Figure 2 shows banding patterns of representative individuals of the 18 species treated with the enzyme MseI. Each sample contains a considerable number of restriction bands, and there are several bands that could not be clearly resolved. Banding patterns of ApoI, AseI, and DraI were expected to be less variable, and they could not discriminate among several species even when results from different enzymes were combined.

In order to simplify the banding patterns to be 
M $123456789101112131415161718 M$

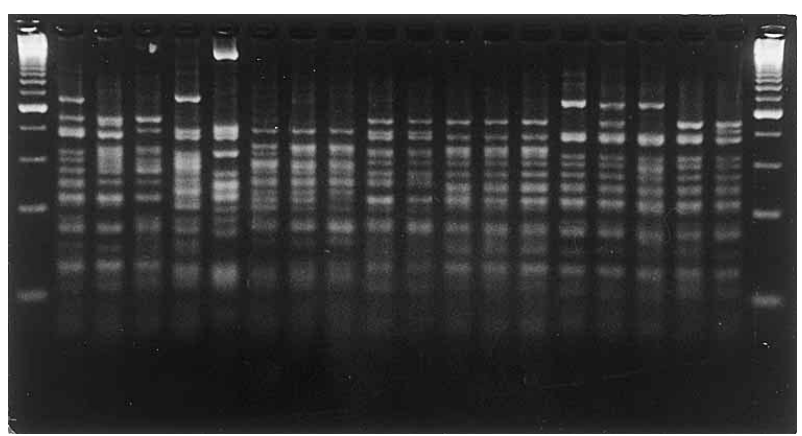

Fig. 2. Banding patterns detected among the 18 Bactrocera species using a PCR-amplified $1.6 \mathrm{~kb}-$ long mtDNA fragment and the restriction enzyme $M s e$ I. Samples were electrophoresed in $4.5 \%$ MetaPhor $^{\mathrm{TM}}$ agarose gel. Lanes: 1: B. carambolae, $2: B$. kandiensis, 3: B. jarvisi, 4: B. depressa, 5: B. tsuneonis, 6: B. cucumis, 7: B. cucurbitae, 8: B. tau, 9: B. frauenfeldi, 10: $B$. psidi, 11: $B$. curvipennis, 12: B. tryoni, 13: B. neohumeralis, 14: B. dorsalis, 15: B. papayae, 16: B. philippinensis, 17: B. occipitalis, 18: B. musae, M: 25 bp-ladder.

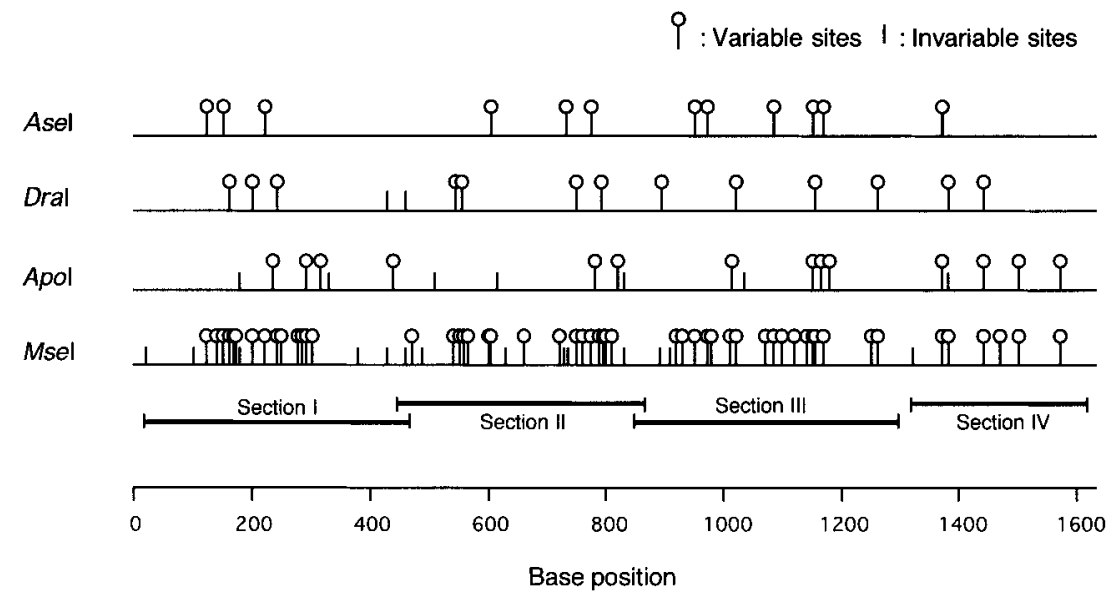

Fig. 3. Recognition sites of representative restriction enzymes expected from 43 nucleotide sequences of the 18 Bactrocera species shown along the length of the mtDNA fragment. Horizontal lines indicate the mtDNA sections used in the PCR-RFLP analyses.

treated in PCR-RFLP analyses, PCR primers were designed to amplify shorter diagnostically informative sections within the mtDNA sequence. Figure 3 shows the distribution of recognition sites of the four most variable enzymes along the length of the DNA sequence. In this figure, variable sites seem to be distributed among four separate sections (bp 150-400, bp 400-900, bp 900-1,300, and bp $1,350-1,600)$. Based on the highly conserved sequences that flank these sections, we designed four sets of PCR primers to amplify these sections separately (Table 2). These primer sets successfully amplified DNA fragments from specimens of all 18 species that had been freshly killed and stored in $99.9 \%$ ethanol. They also worked effectively when
Table 2. PCR primers designed to amplify four different sections within the $1.6 \mathrm{~kb}$-long mtDNA sequence shown in the $5^{\prime}-3^{\prime}$ direction

\begin{tabular}{cll}
\hline Section & Primer & \multicolumn{1}{c}{ Sequence } \\
\hline \multirow{2}{*}{ I } & AFP2 & ATCCAACATCGAGGTCGCAAAC \\
& ARP1 & GGCTGGTATGAACGGTTGGACGAG \\
II & BFP2 & CTCGTCCAACCGTTCATACCAGCC \\
& BRP2 & GTTATTCGTTTATAAAGGTATCT \\
III & CFP2 & AAACTAGATACCTTTATAAAC \\
& CRP1 & GTAACATAGTAGATGTACCGGAA \\
IV & DFP1 & TAATGAGAGCGACGGGCGAT \\
& DRP2 & GGAACCTGTCCTGTAATTGATAAT \\
\hline
\end{tabular}


Table 3. Restriction fragment length estimated among 43 sequences of 18 Bactrocera species $^{\mathrm{a}}$

\begin{tabular}{|c|c|c|c|c|c|c|c|c|c|}
\hline & & Section I & & Section II & & & ection III & & Section IV \\
\hline \multirow[t]{5}{*}{ ApoI } & A: 149 & $13947 \quad 12$ & A: 199156 & $\begin{array}{llll}102 & 43 & 13 & 10\end{array}$ & $\mathrm{~A}: 261$ & 184 & & & A: 23662 \\
\hline & B: 149 & $\begin{array}{llll}112 & 47 & 27 & 12\end{array}$ & B: 163156 & 1024843 & $\mathrm{~B}: 261$ & 164 & 19 & & B: $23647 \quad 16$ \\
\hline & C: 148 & $\begin{array}{llll}81 & 58 & 47 & 12\end{array}$ & C: 163156 & $10243 \quad 3513$ & $C: 164$ & 142 & 11919 & & C: 1896247 \\
\hline & D: 149 & $58 \quad 544739$ & D: 163102 & $8671 \quad 48 \quad 43$ & D:164 & 134 & 12819 & & D: $\begin{array}{llll}189 & 47 & 47 & 16\end{array}$ \\
\hline & E: 149 & $\begin{array}{lllll}58 & 54 & 47 & 27 & 12\end{array}$ & E: 163102 & $\begin{array}{lllll}86 & 71 & 43 & 35 & 13\end{array}$ & E:164 & 119 & 1142919 & & E: $\begin{array}{lllll}76 & 62 & 57 & 54 & 47\end{array}$ \\
\hline \multirow[t]{6}{*}{ DraI } & A: 212 & 135 & A: 40183 & & A:348 & 51 & 45 & & A: $182 \quad 60 \quad 55$ \\
\hline & B: 218 & 129 & B: 31984 & 8329 & $\mathrm{~B}: 301$ & 98 & 45 & & B: 309 \\
\hline & C: 179 & 13533 & C: 31983 & 7930 & $\mathrm{C}: 270$ & 123 & 51 & & \\
\hline & D: 168 & 12950 & D: 31190 & 8328 & $\mathrm{D}: 250$ & 98 & 5145 & & \\
\hline & E: 135 & 1295033 & E: 278123 & 8329 & $\mathrm{E}: 225$ & 123 & 5145 & & \\
\hline & $\mathrm{F}: 347$ & & & & $\mathrm{~F}: 127$ & 123 & 985145 & & \\
\hline \multirow[t]{9}{*}{ AseI } & A: 228 & 119 & A: 369144 & & A:337 & 107 & & & A: 24749 \\
\hline & B: 228 & 9623 & B: 249167 & 96 & $\mathrm{~B}: 233$ & 211 & & & B: 297 \\
\hline & C: 150 & 11978 & C: 249144 & 119 & $\mathrm{C}: 173$ & 160 & 107 & & \\
\hline & D: 150 & 967823 & D: 249119 & 9648 & $\mathrm{D}: 173$ & 128 & 1072115 & & \\
\hline & E: 347 & & & & $\mathrm{E}: 149$ & 111 & $107 \quad 62 \quad 15$ & & \\
\hline & & & & & $F: 128$ & 126 & $107 \quad 62 \quad 21$ & & \\
\hline & & & & & $\mathrm{G}: 128$ & 126 & 10784 & & \\
\hline & & & & & $\mathrm{H}: 128$ & 111 & 1078415 & & \\
\hline & & & & & $\mathrm{I}: 128$ & 111 & $107 \quad 62 \quad 21$ & 15 & \\
\hline \multirow[t]{13}{*}{$M s e \mathrm{I}^{\mathrm{b}}$} & A: 92 & $785744 \quad 41$ & A: 135 & 524535 & A: 128 & 76 & $50 \quad 40 \quad 30$ & & A: $140 \quad 55 \quad 49 \quad 43 \quad 10$ \\
\hline & B: 92 & $78 \quad 57 \quad 50 \quad 44$ & B: 10993 & 524535 & $\mathrm{~B}: 103$ & 59 & 504640 & & B: $\begin{array}{llllll}110 & 55 & 49 & 43 & 30 & 10\end{array}$ \\
\hline & C: 92 & $78 \quad 44 \quad 4133$ & C: 10967 & $52 \quad 45 \quad 35$ & $\mathrm{C}: 103$ & 98 & 545450 & 46 & C: $\begin{array}{llllll}71 & 55 & 49 & 43 & 38 & 30\end{array}$ \\
\hline & D: 92 & 784433 & D: 106 & $52 \quad 45 \quad 35$ & D: 98 & 59 & $5046 \quad 40$ & 36 & D: $\begin{array}{lllll}71 & 69 & 59 & 55 & 43\end{array}$ \\
\hline & E: 88 & 787741 & E: 93 & $\begin{array}{llll}52 & 45 & 43 & 35\end{array}$ & E: 98 & 59 & 504640 & & E: 309 \\
\hline & F: 88 & 78444133 & F: 9360 & $5248 \quad 45$ & $\mathrm{~F}: 82$ & 71 & 504640 & & \\
\hline & G: 88 & 784433 & G: 93 & $\begin{array}{lllll}58 & 52 & 49 & 45 & 35\end{array}$ & G: 82 & 59 & 545046 & & \\
\hline & $\mathrm{H}: 88$ & $7844 \quad 41$ & $\mathrm{H}: 84$ & $52 \quad 45 \quad 41$ & $\mathrm{H}: 82$ & 59 & 504640 & & \\
\hline & I: 78 & $735957 \quad 44$ & I: 84 & 524945 & I: 82 & 52 & $50 \quad 50 \quad 46$ & 27 & \\
\hline & & & J: $84 \quad 58$ & $\begin{array}{llll}52 & 50 & 45 & 35\end{array}$ & $\mathrm{~J}: 82$ & 52 & $5050 \quad 46$ & & \\
\hline & & & & & $\mathrm{K}: 82$ & 50 & $50 s 4640$ & 3727 & \\
\hline & & & & & L: 82 & 50 & 504640 & & \\
\hline & & & & & M: 72 & 52 & $50 \quad 5046$ & 27 & \\
\hline
\end{tabular}

${ }^{\text {a }}$ The length of each fragment was averaged.

${ }^{\mathrm{b}}$ Restriction fragments shorter than 25 (Sections I and III) or $30 \mathrm{bp}$ (Section II) were ignored.

template DNA obtained from dried specimens of $B$. dorsalis and B. cucurbitae left at room temperature for more than 4 months were used (data not shown). In this study, the four sections were denoted as sections I, II, III, and IV. They corresponded to bp 12,948-13,291, 13,268-13,778, 13,751-14,192, and 14,209-14,504 of the $D$. yakuba sequence (X03240), respectively.

Table 3 shows the length of restriction fragments expected among the 43 sequences when the four DNA sections were treated separately with restriction enzymes ApoI, AseI, DraI, and MseI. Banding patterns expected for each species are presented in Table 4. In this table, no single section could discriminate among all the species. However, when results from different sections are combined, species-specific patterns are seen in all species. Based on these results, the method for Bactrocera species identification was designed (Fig. 4). In this scheme, five of the 18 species are clearly identified by banding patterns generated using the sections I and $M s e I$, and the remaining species are separated by one or two further analyses.

Figure 5 shows banding patterns of representa- 
Table 4. Banding patterns expected for the four sections of the mtDNA treated with four different restriction enzymes ${ }^{\mathrm{a}, \mathrm{b}}$

\begin{tabular}{|c|c|c|c|c|c|c|c|c|c|c|c|c|c|c|c|c|}
\hline \multirow{2}{*}{ Species } & \multicolumn{4}{|c|}{ Section I } & \multicolumn{4}{|c|}{ Section II } & \multicolumn{4}{|c|}{ Section III } & \multicolumn{4}{|c|}{ Section IV } \\
\hline & ApoI & DraI & AseI & MseI & ApoI & DraI & AseI & MseI & ApoI & DraI & AseI & MseI & ApoI & DraI & AseI & MseI \\
\hline B. frauenfeldi & $\mathrm{E}$ & A & A & $\mathrm{C}$ & B & $\mathrm{B}$ & $\mathrm{C}$ & $\mathrm{E}$ & $\mathrm{C}$ & $\mathrm{D}$ & $\mathrm{F}$ & $\mathrm{J}$ & $\mathrm{E}$ & A & A & B \\
\hline B. psidi & $\mathrm{E}$ & $\mathrm{E}$ & A & $\mathrm{C}$ & $\mathrm{B}$ & B & $\mathrm{C}$ & $\mathrm{E}$ & $\mathrm{C}$ & $\mathrm{D}$ & $\mathrm{F}$ & $\mathrm{L}$ & $\mathrm{E}$ & A & A & B \\
\hline B. jarvisi & $\mathrm{E}$ & $\mathrm{C}$ & B & $\mathrm{D}$ & $\mathrm{C}$ & A & $\mathrm{C}$ & $\mathrm{C}$ & $\mathrm{C}$ & $\mathrm{D}$ & I & $\mathrm{F}$ & $\mathrm{E}$ & A & B & B \\
\hline B. curvipennis & $\mathrm{E}$ & A & $\mathrm{D}$ & G & B & $\mathrm{C}$ & $\mathrm{C}$ & $\mathrm{J}$ & $\mathrm{E}$ & $\mathrm{D}$ & G & G & $\mathrm{E}$ & A & A & B \\
\hline B. tryoni & $\mathrm{D}$ & A & $\mathrm{D}$ & G & B & $\mathrm{C}$ & $\mathrm{C}$ & $\mathrm{J}$ & $\mathrm{E}$ & $\mathrm{D}$ & $\mathrm{H}$ & $\mathrm{H}$ & $\mathrm{E}$ & A & A & B \\
\hline B. neohumeralis & $\mathrm{E}$ & A & $\mathrm{D}$ & $\mathrm{G}$ & B & $\mathrm{C}$ & $\mathrm{C}$ & $\mathrm{J}$ & $\mathrm{E}$ & $\mathrm{D}$ & $\mathrm{H}$ & $\mathrm{H}$ & $\mathrm{E}$ & A & A & $\mathrm{B}$ \\
\hline B. cucumis & $\mathrm{C}$ & A & A & A & B & A & $\mathrm{B}$ & I & B & $\mathrm{E}$ & $\mathrm{D}$ & $\mathrm{M}$ & $\mathrm{D}$ & A & A & $\mathrm{D}$ \\
\hline B. musae & $\mathrm{E}$ & $\mathrm{E}$ & $\mathrm{C}$ & $\mathrm{H}$ & $\mathrm{C}$ & $\mathrm{E}$ & $\mathrm{C}$ & $\mathrm{B}$ & $\mathrm{C}$ & A & $\mathrm{E}$ & $\mathrm{B}$ & $\mathrm{E}$ & A & A & $\mathrm{B}$ \\
\hline B. dorsalis & $\mathrm{E}$ & $\mathrm{E}$ & $\mathrm{C}$ & $\mathrm{H}$ & $\mathrm{C}$ & $\mathrm{E}$ & A & A & $\mathrm{C}$ & $\mathrm{D}$ & $\mathrm{E}$ & E & $\mathrm{E}$ & A & A & A \\
\hline B. papayae & $\mathrm{E}$ & $\mathrm{E}$ & $\mathrm{C}$ & $\mathrm{H}$ & $\mathrm{C}$ & $\mathrm{E}$ & A & $\mathrm{A}$ & $\mathrm{C}$ & $\mathrm{D}$ & $\mathrm{E}$ & $\mathrm{E}$ or $\mathrm{D}^{*}$ & $\mathrm{E}$ & $\mathrm{A}$ & $\mathrm{A}$ & $\mathrm{B}$ \\
\hline B. philippinensis & $\mathrm{E}$ & $\mathrm{E}$ & $\mathrm{C}$ & $\mathrm{H}$ & $\mathrm{C}$ & $\mathrm{E}$ & A & A & $\mathrm{C}$ & $\mathrm{D}$ & $\mathrm{E}$ & E & $\mathrm{E}$ & A & A & $\mathrm{C}$ \\
\hline B. occipitalis & $\mathrm{E}$ & $\mathrm{C}$ & $\mathrm{C}$ & $\mathrm{H}$ & $\mathrm{C}$ & $\mathrm{E}$ & $\mathrm{C}$ & $\mathrm{B}$ & $\mathrm{C}$ & $\mathrm{D}$ & $\mathrm{E}$ & D & $\mathrm{E}$ & A & A & B \\
\hline B. carambolae & $\mathrm{E}$ & $\mathrm{E}$ & A & $\mathrm{F}$ & $\mathrm{C}$ & $\mathrm{E}$ & A & A & $\mathrm{C}$ & $\mathrm{D}$ & $\mathrm{E}$ & $\mathrm{E}$ or $\mathrm{D}^{*}$ & $\mathrm{E}$ & A & A & B \\
\hline B. kandiensis & B & $\mathrm{D}$ & A & $\mathrm{E}$ & $\mathrm{C}$ & $\mathrm{E}$ & $\mathrm{C}$ & $\mathrm{D}$ & $\mathrm{C}$ & $\mathrm{D}$ & I & F & E & A & A & B \\
\hline B. cucurbitae & $\mathrm{C}$ & A & A & A & $\mathrm{E}$ & A & $\mathrm{D}$ & $\mathrm{H}$ & B & $\mathrm{F}$ & $\mathrm{D}$ & I & $\mathrm{B}$ or $\mathrm{D}^{*}$ & A & A & $\mathrm{D}$ \\
\hline B. tau & $\mathrm{C}$ & A & A & A & $\mathrm{E}$ & $\mathrm{A}$ & $\mathrm{D}$ & $\mathrm{H}$ & B & $\mathrm{F}$ & $\mathrm{D}$ & $\mathrm{K}$ & B & $\mathrm{A}$ & A & $\mathrm{D}$ \\
\hline \multirow[t]{2}{*}{ B. depressa } & A & B & $\mathrm{E}$ & B & $\mathrm{D}^{*}$ & $\mathrm{D}^{*}$ & $\mathrm{C}$ & $\mathrm{F}$ & $\mathrm{D}$ & $\mathrm{C}$ & $\mathrm{A}^{*}$ & A & $\mathrm{C}$ & $A^{*}$ & A & $\mathrm{D}$ \\
\hline & A & B & $\mathrm{E}$ & $\mathrm{B}$ & $\mathrm{E}^{*}$ & $\mathrm{~A}^{*}$ & $\mathrm{C}$ & $\mathrm{F}$ & $\mathrm{D}$ & $\mathrm{C}$ & $\mathrm{C}^{*}$ & A & $\mathrm{C}$ & $\mathrm{B}^{*}$ & A & $\mathrm{D}$ \\
\hline B. tsuneonis & A & $\mathrm{F}$ & $\mathrm{E}$ & I & $\mathrm{A}$ & $\mathrm{D}$ & $\mathrm{C}$ & $\mathrm{F}$ & A & B & B & $\mathrm{C}$ & A & $\mathrm{B}$ & A & $\mathrm{E}$ \\
\hline
\end{tabular}

${ }^{a}$ Characters A-M refer to the restriction fragment patterns defined in Table 3.

${ }^{\mathrm{b}}$ Asterisks refer to intraspecific variations.

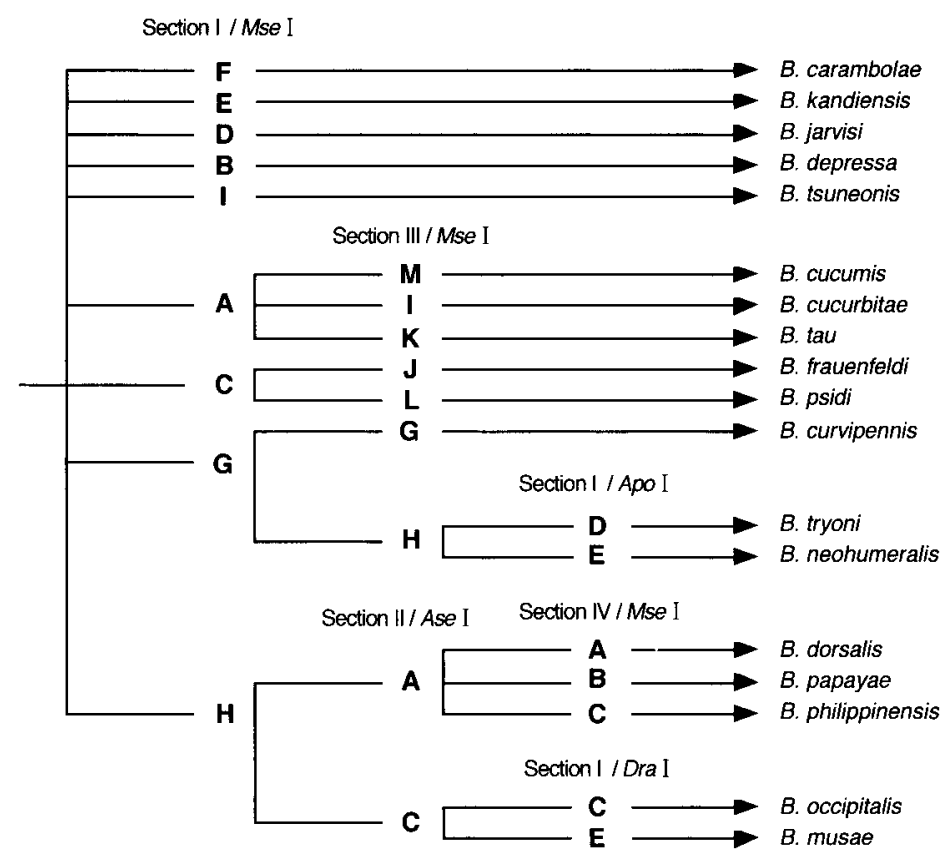

Fig. 4. Scheme for the Bactrocera species identification based on PCR-RFLP patterns estimated for the four sections of the mtDNA fragment. Characters A-M refer to the banding patterns defined in Table 3.

tive individuals of the 18 species obtained using diagnostic mtDNA sections and the restriction enzymes shown in Fig. 4. When compared with the image shown in Fig. 2, banding patterns became simpler and are considered to be suitable for discrimination of different restriction fragments. In 
A) Section I / Mse I

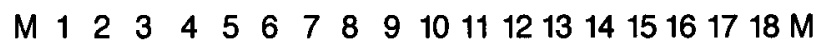

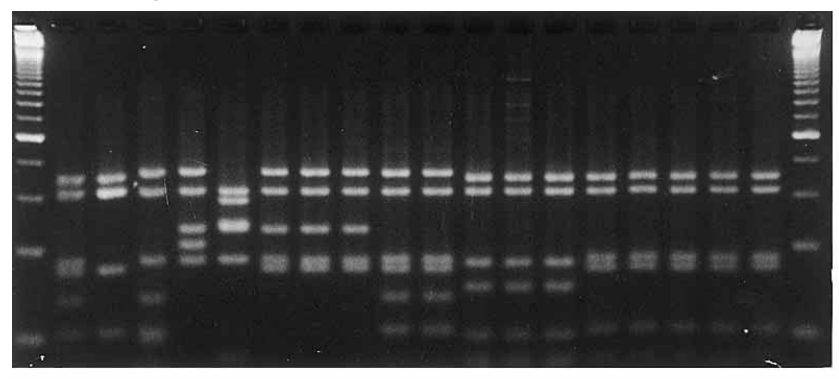

B) Section III / Mse I

M $67 \begin{array}{llll} & 9 & 1011 & 1213 M\end{array}$

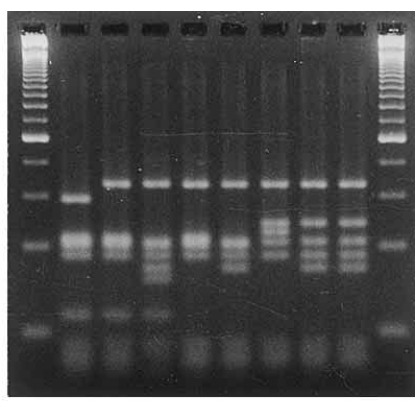

C) Section I/ Apo I

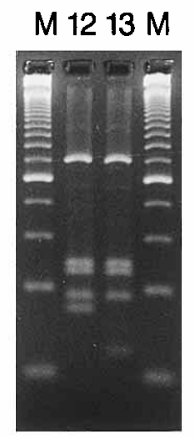

D) Section II / Ase I

M $1415161718 \mathrm{M}$

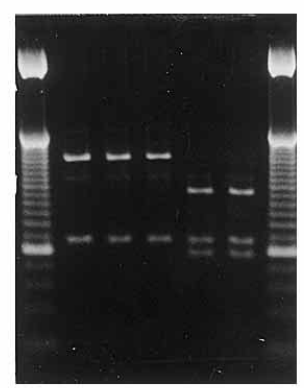

E) Section IV / Mse I

$M 141516 \mathrm{M}$

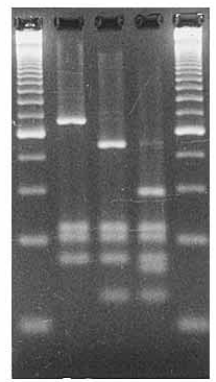

F) Section I / Dra I

M $1718 \mathrm{M}$

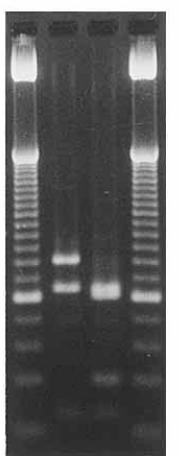

Fig. 5. Banding patterns detected among the 18 Bactrocera species using PCR-amplified mtDNA sections and restriction en-

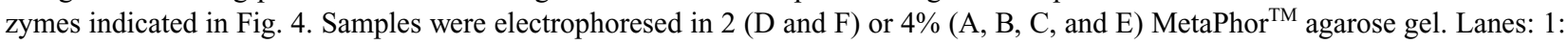
B. carambolae, 2: B. kandiensis, 3: B. jarvisi, 4: B. depressa, 5: B. tsuneonis, 6: B. cucumis, 7: B. cucurbitae, 8: B. tau, 9: B. frauenfeldi, 10: B. psidi, 11: B. curvipennis, 12: B. tryoni, 13: B. neohumeralis, 14: B. dorsalis, 15: B. papayae, 16: B. philippinensis, 17: B. occipitalis, 18: B. musae, M: 25 bp-ladder.

this analysis, banding patterns of 83 individuals were compared and no intra-specific variation was observed except in the case of $B$. carambolae in which six of the nine specimens examined showed the same banding patterns as B. papayae. Thus, the analysis confirmed that the scheme proposed in Fig. 4 could be applied to almost all individuals of the species treated in this study.

\section{DISCUSSION}

\section{Phylogeny}

In the molecular phylogenetic analyses, topologies generated by the neighbor-joining and maximum parsimony methods agreed very well. Although most of the phylogenetic relationships were supported by relatively high bootstrap confidence levels, molecular phylogenetic trees disagreed in part with the currently accepted morphological classification (Hardy and Foote, 1989; White and Hancock, 1997). Among five subgenera included in the analyses, monophylies of subgenera Bactrocera and Zeugodacus were revealed to be questionable. The monophyly of the subgenus Zeugodacus was violated by a close relationship between $B$. (Austrodacus) cucumis and B. (Zeugodacus) cucurbitae $+B$. (Z.) tau. In all the phylogenetic trees obtained in this study, B. (Afrodacus) jarvisi was always positioned within the clade including $B$. (Bactrocera) species. Unexpected relationships were also detected between $B$. musae and species of the $B$. dorsalis complex. The $B$. dorsalis complex species, $B$. dorsalis, B. papayae, B. carambolae, $B$. philippinensis, and $B$. occipitalis, always showed a closer relationship with $B$. musae than with the other members of the complex, B. kandi- 
ensis.

As in many other genera belonging to the subfamily Dacinae, classification of Bactrocera taxa has long been complicated. Before Drew (1989) proposed the current status of taxa within the genus, taxonomic positions of this and related groups had been changed many times. Our results are considered to reflect such a situation and to support the view of Drew (1989) that the supraspecific classification of the subfamily is unsettled. The present study strongly demonstrated the necessity of closer analyses of morphological characteristics and of new criteria, such as nucleotide sequences, to test the morphologically based classification.

\section{Species identification}

In this study, we considered a PCR-RFLP-based method of Bactrocera species identification based on nucleotide sequences of the mtDNA. Using the spacer (ITS) region of the nuclear ribosomal DNA, Armstrong et al. (1997) also analyzed PCR-RFLPs of fruit fly species of quarantine importance in New Zealand. However, because they used PCRprimers designed to amplify a relatively long DNA fragment $(3-3.5 \mathrm{~kb})$, their primers were sometimes difficult to use for DNA samples obtained from specimens left under protracted bad conditions (Muraji, unpublished). In addition, because nucleotide sequences of ITS and the flanking regions were known for only a small number of species of this insect group, it has been difficult to redesign PCR primers to analyze shorter sections within the DNA fragment. In the present study, we determined diagnostically useful PCR primers and restriction enzymes based on nucleotide sequences of a number of Bactrocera species. However, we could not confirm the applicability of the method for a wide variety of Bactrocera species. As discussed below, the applicability of such a method is determined by several aspects included in the experimental procedure. The method proposed in this study was devised to deal with such restrictions.

For analyses performed in quarantine practices, the PCR primers must work with samples stored or left under a variety of conditions and must be able to amplify DNA fragments from a variety of species. Thus, we designed the primers to amplify short sections within the sequence, because PCR usually works effectively when a short DNA frag- ment is amplified. We designed the primers based on highly conserved sequences detected among various Bactrocera taxa. The results of PCR reflected these considerations, and indicated that these primers could work well with DNA template extracted from various Bactrocera species and from dried specimens left under protracted room conditions. Because our primers also work with Dipteran flies of several other groups, such as the Anastrepha and Drosophila (data not shown), they are expected to be applicable for a wide variety of Bactrocera species.

For rapid analysis of restriction fragments, banding patterns should be as simple as possible. Because the resolution of different-size DNA fragments depends on the concentration of agarose gel (Sambrook et al., 1989), it is often difficult to determine the size of various bands simultaneously. Because we used relatively short sections of the mtDNA (296-515 bp) in restriction analyses, this problem was to some extent avoided. On the other hand, these mtDNA sections frequently generated very short restriction fragments, which could not be separated by usual agarose gel electrophoresis. However, we confirmed that a $3 \mathrm{bp}$ difference between DNA bands of about $40 \mathrm{bp}$ in length was clearly detected by agarose gel electrophoresis using a special kind of agarose developed for separation of small DNA fragments (see Materials and Methods).

In order to assure the applicability of the method for a wide variety of Bactrocera species, banding patterns should be as variable as possible. However, because mtDNA sequences are available only for a relatively small number of species, we could not, at this point, confirm the usefulness of the method. However, given that all the sequences used were submitted to international DNA databases accessible on the World Wide Web, researchers can easily test and redesign the scheme for species identification in the event that they obtain the sequence of Bactrocera not included in this study.

In this study, PCR-RFLP analyses could not discriminate between $B$. papayae and the majority of individuals of $B$. carambolae. However, such individuals showed banding patterns specific to $B$. carambolae when the spacer region of the nuclear ribosomal DNA was analyzed (Muraji, unpublished). Thus, such individuals may be hybrids or interbreeding descendants between the closely re- 
lated sympatric species within the $B$. dorsalis complex. In fact, several researchers have suggested the possibility of interbreeding and introgression among sibling species within this insect group (Yong, 1995; Iwaizumi et al., 1997; McInnis et al., 1999). In order to confirm the genetic interrelationship among the $B$. dorsalis complex species, analyses of field populations using many other genetic markers are needed. Such information could help confirm the reliability and accuracy of the PCRRFLP-based method of species identification of this insect group.

\section{ACKNOWLEDGEMENTS}

We thank Mr. Robert Corcoran of the Queensland Horticulture Institute, Australia, and Dr. David J. Rogers of the Horticulture and Food Research Institute of New Zealand Ltd., New Zealand, for supplying materials sequenced in this study. Mr. M. Narahara of the Oita Prefectural Citrus Experiment Station, Mr. Y. Kobashigawa and Mr. M. Sasaki of the Naha Plant Protection Office, Mr. T. Kawashita and Mr. R. Iwaizumi of the Yokohama Plant Protection Station, and Dr. O. Iwahashi of University of the Ryukyus kindly provided specimens used in PCR-RFLP analyses. Mr. T. Sugimoto and Mr. M. Kaneda of the Yokohama Plant Protection Station gave us useful suggestions. This work is part of a project supported by the Budget for Nuclear Research of the Ministry of Education, Culture, Sports, Science and Technology, Japan.

\section{REFERENCES}

Armstrong, K. F., C. M. Cameron and E. R. Frampton (1997) Fruit fly (Diptera: Tephritidae) species identification: a rapid molecular diagnostic technique for quarantine application. Bull. Entomol. Res. 87: 111-118.

Drew, R. A. I. (1989) The tropical fruit flies (Diptera: Tephritidae: Dacinae) of the Australian and Oceanian regions. Mem. Queensl. Mus. 26: 1-521.

Han, H.-Y. (2000) Molecular phylogenetic study of the tribe Trypetini (Diptera: Tephritidae) using mitochondrial 16S ribosomal DNA sequences. Biochem. Syst. Ecol. 28: 501-513.

Han, H.-Y. and B. A. McPheron (1997) Molecular phylogenetic study of Tephritidae (Insecta: Diptera) using partial sequences of the mitochondrial 16S ribosomal DNA. Mol. Phylogenet. Evol. 7: 17-32.

Hardy, D. E. and R. H. Foote (1989) Family Tephritidae. In Catalog of the Diptera of the Australasian and Oceanian Regions (N. L. Evenhuis ed.). Bishop Museum Press, Honolulu, pp. 502-531.

Hein, J. J. (1990) A unified approach to alignment and phylogenies. Methods Enzymol. 183: 626-645.

Iwaizumi, R., M. Kaneda and O. Iwahashi (1997) Correlation of length of terminalia of males and females among nine species of Bactrocera (Diptera: Tephritidae) and differences among sympatric species of $B$. dorsalis complex. Ann. Entomol. Soc. Am. 90: 664-666.

Kumar, S., K. Tamura and M. Nei (1993) MEGA: Molecular Evolutionary Genetics Analysis, version 1.01. The Pennsylvania State University, University Park, Pennsylvania.

McInnis, D. O., P. Rendon, E. Jang, A. van Sauers-Muller, R. Sugiyama and A. Malavasi (1999) Interspecific mating of introduced, sterile Bactrocera dorsalis with wild $B$. carambolae (Diptera: Tephritidae) in Suriname: a potential case for cross-species sterile insect technique. Ann. Entomol. Soc. Am. 92: 758-765.

Muraji, M. and S. Nakahara (2001) Phylogenetic relationships among fruit flies, Bactrocera (Diptera, Tephritidae), based on the mitochondrial rDNA sequences. Insect. Mol. Biol. 10: 549-559.

Sambrook, J., E. F. Fritsch and T. Maniatis (1989) Molecular Cloning: A Laboratory Manual. 2nd ed., Vol. 1. Cold Spring Harbor Laboratory Press, Cold Spring Harbor, New York. 787 pp.

Smith, J. J. and G. L. Bush (1997) Phylogeny of the genus Rhagoletis (Diptera: Tephritidae) inferred from DNA sequences of mitochondrial cytochrome oxidase II. Mol. Phylogenet. Evol. 7: 33-43.

Swofford, D. L. (1999) PAUP*. Phylogenetic Analysis Using Parsimony (*and Other Methods), Version 4. Sinauer Associates, Sunderland, Massachusetts.

White, I. M. and D. L. Hancock (1997) CABIKEY to the Dacini (Diptera, Tephritidae) of the Asian, Pacific, and Australasian Regions. CAB International, Wallingford, Oxfordshire.

Yong, H. S. (1995) Genetic differentiation and relationships in five taxa of the Bactrocera dorsalis complex (Insecta: Diptera: Tephritidae). Bull. Entomol. Res. 85: 431-435.

Yoshizawa, O. (1997) Successful eradication programs on fruit flies in Japan. Res. Bull. Pl. Prot. Jpn. 33 (Suppl.): 1-10. 